UDC 343.9

LBC 67.51

\title{
THE REGIONAL STRATEGY OF THE NATIONAL SECURITY OF THE SOUTH OF RUSSIA: CONFRONTATION OF CIVIL ASSOCIATIONS WITH CRIMINAL THREATS
}

\author{
Pavel P. Fantrov \\ Volgograd State University, Volgograd, Russian Federation \\ Vladimir M. Shinkaruk \\ Volgograd State University, Volgograd, Russian Federation
}

\begin{abstract}
Introduction: the South of Russia is an important strategic region, reflecting the structural elements of Russian geopolitics and, thus, almost the entire range of existing threats to the national security, including the criminal ones. The active participation of the civil society structures in the suppression and prevention of criminal threats can contribute to improving the level of the national security, in this connection, it is necessary to strengthen the legal and regulatory role of the citizens in the regional strategies of the national security. Methods: the authors use the following methods of scientific cognition: the general scientific ones (analysis, synthesis, induction, deduction, modeling); the institutional one, allowing to study the role of the subjects of the system of ensuring the national security of the South of Russia; the system-structural ones, whereby it is possible to distinguish a set of stable communications between the components of the national security system; case-study used to analyze the situations that arise when implementing the technologies of interaction of actors in the context of combating criminal threats. Results: by means of the secondary analysis of the official data of the Prosecutor General of the Russian Federation the most pressing criminal threats to the national security in the South of Russia, which should include terrorism, extremism and corruption, have been identified. It is noted that the civil associations together with the law enforcement agencies are able to resist these threats, using the technologies of public control, a systemic political dialogue, crowd sourcing, socializing and PR-technologies. Conclusions: as a result of the conducted research it is established that it is expedient to include the regional strategies in the national security system fixing them in the normative legal acts of the subjects of the South of Russiaand reflecting the role of the civil society structures in countering criminal threats, as well as the technologies of interaction between the state and society, corresponding to the principles of political participation of citizens, value consolidation, equality of opportunities of civil solidarity and cross-cultural interaction.
\end{abstract}

Key words: national security, law enforcement, civil society, criminal threats, extremism, terrorism, corruption.

УДК 343.9

ББК 67.51

\section{РЕГИОНАЛЬНЫЕ СТРАТЕГИИ НАЦИОНАЛЬНОЙ БЕЗОПАСНОСТИ ЮГА РОССИИ: ПРОТИВОСТОЯНИЕ ГРАЖДАНСКИХ АССОЦИАЦИЙ КРИМИНАЛЬНЫМ УГРОЗАМ}

\author{
Павел Петрович Фантров \\ Волгоградский государственный университет, г. Волгоград, Российская Федерация \\ Владимир Маркович Шинкарук \\ Волгоградский государственный университет, г. Волгоград, Российская Федерация
}


Введение: Юг России является важным стратегическим регионом, отражающим структурные элементы геополитики РФ и тем самым практически весь спектр существующих угроз национальной безопасности, в том числе и криминальных. Активное участие структур гражданского общества в пресечении и предотвращении криминальных угроз может способствовать повышению уровня национальной безопасности, в связи с чем необходимо нормативно-правовое закрепление роли граждан в региональных стратегиях национальной безопасности. Методы: авторами используются следующие методы научного познания: общенаучные (анализ, синтез, индукция, дедукция, моделирование); институциональный, позволяющий исследовать роль субъектов системы обеспечения национальной безопасности Юга России; системно-структурный, с помощью которого можно выделить совокупность устойчивых коммуникаций между компонентами системы национальной безопасности; case-study, применяемый для анализа ситуаций, складывающихся при реализации технологий взаимодействия акторов в контексте борьбы с криминальными угрозами. Результаты: с помощью вторичного анализа официальных данных Генпрокуратуры РФ выявлены наиболее актуальные криминальные угрозы национальной безопасности Юга России, к которым следует отнести терроризм, экстремизм и коррупцию. Отмечено, что ассоциации граждан совместно с правоохранительными органами способны противостоять данным угрозам, применяя технологии общественного контроля, системного политического диалога, краудсорсинга, социализирующие и PR-технологии. Выводы: в результате проведенного исследования установлено, что в систему обеспечения национальной безопасности целесообразно включить региональные стратегии, закрепив их в нормативных правовых актах субъектов Юга России и отразив в них роль структур гражданского общества в противодействии криминальных угроз, а также технологии взаимодействия государства и общества, соответствующие принципам политического участия граждан, ценностной консолидации, равенства возможностей гражданской солидарности и кросс-культурного взаимодействия.

Ключевые слова: национальная безопасность, правоохранительные органы, гражданское общество, криминальные угрозы, экстремизм, терроризм, коррупция.

\section{Введение}

Несмотря на наличие Стратегии национальной безопасности России, ее осуществление на региональном уровне требует разработки региональных мер с учетом их специфики и местных реалий. Активное участие ассоциаций граждан в защите национальных интересов и отстаивании национальных приоритетов в настоящее время становится все более актуальным [1, с. 76].

Для Юга России, включающего субъекты Северо-Кавказского и Южного федеральных округов, борьба с преступлениями экстремистской и террористической направленности и коррупцией являются актуальными направлениями обеспечения национальной безопасности. Согласно вторичному анализу данных Генеральной прокуратуры России за 2017 г., наименее безопасным регионом России является Северо-Кавказский федеральный округ (СКФО) вследствие большого числа зарегистрированных преступлений экстремистского характера и террористической направленности $(61,25 \%$ от их общего количества по всей стране). На втором месте в связи с количеством совершенных преступлений подобного рода находится Южный федеральный округ (ЮФО $)^{1}$.

\section{Использование технологии краудсорсинга в деятельности гражданских ассоциаций по противодействию криминальным угрозам}

При формировании региональной стратегии национальной безопасности Юга России органам законодательной власти необходимо сделать акцент на мерах по противодействию экстремизму и терроризму с привлечением общественности. Это позволит более широко внедрять в правоприменительную практику инновационную технологию краудсорсинга, которая предполагает апробированный алгоритм действий групп интернет-пользователей в целях совместного выявления сетевых сообществ, специализирующихся на распространении противоправного контента. Подобные ассоциации граждан оказывают существенную поддержку правоохранительным органам, реализуя краудсорсинговые проекты по профилактике экстремизма и терроризма [3, с. 45]. Среди них следует выделить ряд крупных общественных объединений федерального значения, осуществляющих такие проекты: Общероссийский народный фронт, Российский союз молодежи, Ассамблея народов России, Межрегиональная ассоциация общественных 
объединений «За солидарность в борьбе с экстремизмом и терроризмом!», Молодая Гвардия Единой России и др.

К наиболее результативным краудсорсинговым проектам, осуществляемым на территории Юга России и ставящим задачу по борьбе с противоправным контентом, следует отнести «STOPTERROR», «МедиаГвардию» и «Кибердружину» [5, с. 233].

Краудсорсинговый проект STOPTERROR, реализуемый Комиссией Общественной палаты России по гармонизации межнациональных и межрелигиозных отношений, в том числе и Юга России, осуществляется в целях мониторинга сети Интернет на наличие информации, содержащей элементы пропаганды терроризма, религиозной и национальной ненависти и вражды. За полтора года ее работы было обработано около 7 тысяч обращений граждан, указывающих на конкретные сетевые ресурсы с деструктивными материалами и призывами. Более тысячи из этих сайтов были закрыты после того, как активисты проекта передали информацию о них в правоохранительные органы, поскольку они публиковали пропагандистские материалы террористической группы ДАИШ, призывы к суициду, инструкции по изготовлению самодельных взрывных устройств и т. д. ${ }^{2}$

Директором ФСБ РФ А.В. Бортниковым было отмечено, что сейчас количество заблокированных источников электронной информации экстремистской и террористической направленности с 2015 г. возросло более чем вдвое ${ }^{3}$. Как видим, данная проблема является актуальной, несмотря на то, что с 2011 г. функционирует межрегиональное молодежное общественное движение «Кибердружина», объединившее свыше 20 тысяч добровольцев и реализующее технологию краудсорсинга. Мониторинг сетевых ресурсов, проведенный кибердружинниками, позволил выявить и заблокировать сотни сайтов с противоправным контентом. Данная ассоциация граждан имеет свои представительства в Северо-Кавказском и Южном федеральном округах.

Серьезный вклад в противодействие сетевому экстремизму и терроризму по-прежнему вносит Молодая Гвардия Единой России, реализующая инновационный краудсорсинговый проект «МедиаГвардия». Если в
2015 г. активисты Молодой Гвардии выявили около 2,5 тысяч сайтов, содержащих информацию экстремистской направленности, то уже в 2016 г. - свыше 20 тысяч сайтов, содержащих противоправный контент ${ }^{4}$, а в 2017 г. - около 20 тысяч ${ }^{5}$. Помимо этого сотрудниками ФСБ с помощью граждан, участвующих в реализации данного проекта, было полностью ликвидировано сообщество, состоящее из более 100 тысяч интернет-последователей, разделяющих идеологию «Исламского государства». В этой связи в рамках региональной стратегии национальной безопасности необходима более масштабная реализация инновационных технологий, способствующих предупреждению и профилактике преступлений террористического и экстремистского характера.

\section{Реализация}

\section{социализирующих технологий \\ в контексте обеспечения национальной безопасности Юга России}

Нормативно-правовое оформление социализирующих технологий совместной деятельности правоохранительных органов и, в частности, народных дружин в современных условиях при разработке региональной стратегии национальной безопасности Юга России имеет значительный потенциал и способно повлиять на изменение криминальной обстановки отдельного региона [5, с. 197]. К примеру, в Волгоградской области в 2017 г. при помощи дружинников пресечены 4735 административных правонарушений и задержано 136 лиц по подозрению в совершении преступлений ${ }^{6}$.

В реализации целого ряда стратегических национальных приоритетов значимую поддержку, в частности, оказывают и казачьи дружины. Их деятельность высоко оценил Президент России В.В. Путин, отметив, что «...казаки играют уникальную и весьма позитивную роль в России» ${ }^{7}$. Принимая участие в реализации социализирующих технологий, данные общественные объединения оказывают содействие полиции в несении патрульно-постовой службы и осуществлении профилактических мероприятий по обеспечению общественного порядка. 


\section{Перспективы совершенствования региональных стратегий} национальной безопасности Юга России

Однако в ряде регионов Юга России (например, Дагестане, Ингушетии и КабардиноБалкарии) еще предстоит сформировать действенную систему участия структур гражданского общества в решении вызовов и угроз национальной безопасности. Результаты опроса граждан, проведенного в 2017 г. пражским информационным агентством «Medium Orient» в этих трех республиках СКФО, имеющих высокий конфликтогенный потенциал, иллюстрируют отдельные серьезные современные проблемы обеспечения национальной безопасности ${ }^{8}$. Так, наиболее актуальной из них, по мнению 34,1 \% респондентов, является коррупция правящих элит. В Республике Дагестан, учитывая позицию проживающих там граждан (39,8 \%), она наиболее значима. Данное положение подтверждается имеющимися данными о том, что лишь 16 из 70 государственных программ развития в Дагестане проводятся с эффективным расходованием целевых федеральных средств, а остальные - не получают должного финансирования: «...деньги недополучили 54 госпрограммы, включая "Обеспечение общественного порядка и противодействия преступности в Республике Дагестан”. Если взвесить 35 миллиардов в пятитысячных купюрах, то вес составит около семи тонн. Деньги потратили, а кто - неизвестно» ${ }^{9}$. Более того, возникают совершенно неприемлемые ситуации, когда весьма влиятельные представители местных региональных элит финансируют деятельность террористических организаций. Например, в июле 2015 г. обвинен в этом глава Пенсионного фонда РФ по Республике Дагестан С. Муртазалиев ${ }^{10}$. Иными словами, в данном субъекте финансовые ресурсы направлялись не на обеспечение российских национальных интересов, а на прямо противоположные им цели. Соответственно региональная стратегия национальной безопасности в этом регионе должна поставить во главу угла борьбу с коррупцией.

Результаты проведенного опроса жителей Дагестана, Ингушетии и Кабардино-Балкарии с вопросом «Считаете ли вы, что права гражданина в вашей республике соблю- даются в полной мере?» отражают проблемы соблюдения прав человека. Так, 67,7 \% опрошенных граждан считают, что их права не реализуются в полной мере, а общее число тех, кто считает, что «они соблюдаются» или «скорее соблюдаются» составляет $29,3 \%{ }^{11}$. Такое положение вещей представляет реальную угрозу безопасности личности и общества [2, с. 107]. При формировании региональной стратегии национальной безопасности оно должно найти свое отражение. В частности, целесообразно продолжить развитие системы общественных правозащитных организаций [4, с. 154] и повсеместно внедрять технологии обеспечения национальной безопасности (гражданский контроль, общественный политический диалог и PRтехнологии), адаптированные к местным социокультурным условиям.

Результаты проведенного опроса свидетельствуют и о низком уровне доверия граждан северокавказских республик к судебной системе. Так, лишь 13,5 \% респондентов считают деятельность судов эффективной ${ }^{12}$. Данная ситуация представляется неприемлемой и крайне неблагоприятной в контексте защиты прав и свобод граждан, поскольку отражает широко распространенное в сознании населения негативное представление о судебной власти как о коррумпированной и часто зависимой от региональных элит. Продемонстрированный опрошенными уровень доверия к международным правозащитным структурам также невысокий - 28,1 \% граждан, в то время как 40,7\% не доверяют им вообще, а $31,2 \%$ респондентов по разным причинам затруднились с оценкой ${ }^{13}$.

Для решения обозначенных проблем и совершенствования региональных стратегий национальной безопасности Юга России, на наш взгляд, необходимо: проводить комплексный мониторинг имеющихся социально-правовых проблем в данной области; ввести регулярную отчетность органов региональной власти и местного самоуправления по вопросам, связанным с защитой прав и свобод граждан от внутренних и внешних угроз; внедрять в правоохранительную практику сетевые проекты, предполагающие коммуникативную связь между силовыми структурами и гражданами; организовывать мероприятия с уча- 
стием представителей органов власти, силовых ведомств и гражданского общества с целью реализации совместных инициатив. Содержание этих рекомендаций обусловливает их законодательное закрепление в региональной стратегии национальной безопасности Юга России, поскольку та должна строиться на принципах равноправного участия граждан в проводимой политике, ценностной консолидации, равенства возможностей гражданской солидарности, а также на кросс-культурном взаимодействии. При этом в контексте повышения уровня региональной безопасности недопустимо ориентироваться на изоляционизм и автаркию этнических систем.

\section{Выводы}

Защита национальных интересов на региональном уровне требует разработки частных (региональных) стратегий обеспечения национальной безопасности в каждом из федеральных округов России, исходя из наличия территориальной специфики и с учетом местных социальных реалий, закрепив их в нормативных правовых актах субъектов России. Это позволило бы оптимально использовать технологии взаимодействия гражданского общества и органов государственной власти при защите национальных интересов в частности, и посредством закрепления следующих компонентов: борьба с терроризмом, экстремизмом и коррупцией; создание условий, способствующих защите конституционных прав и свобод граждан; предотвращение этнических и религиозных конфликтов; нейтрализация всех центробежных сил, угрожающих суверенитету России.

\section{ПРИМЕЧАНИЯ}

1 Показатели преступности России. URL: http://crimestat.ru/offenses_map (дата обращения: 14.04.2018).

2 Проект STOPTERROR: промежуточные итоги. URL: https://www.oprf.ru/press/news/2017/ newsitem/40861 (дата обращения: 14.04.2018).

${ }^{3}$ НАК отчитался о выявлении 26 тысяч экстремистских и террористических сайтов. URL: https:// meduza.io/news/2016/12/13/nak-otchitalsya-ovyyavlenii-26-tysyach-ekstremistskih-i-terroristicheskihsaytov (дата обращения: 14.04.2018).
4 «Молодая гвардия» за год добилась блокировки 20 тыс. сайтов с незаконным контентом. URL: http://vz.ru/news/2016/12/15/849613.html (дата обращения: 14.04.2018).

5 Анна Рогачева: «МедиаГвардия» спасает не только чистоту интернета, но и жизни людей. URL: http://www.molgvardia.ru/nextday/2017/12/31/94005 (дата обращения: 14.04.2018).

${ }^{6}$ Информация об участии граждан в охране общественного порядка на территории Волгоградской области по итогам работы за 12 месяцев 2017 года. URL: https://34.мвд.pф/document/12004630 (дата обращения: 14.04.2018).

7 Президент РФ Владимир Путин о казаках. URL: http://skvskr.ucoz.net/publ/internet/sajt/ prezident_rf_vladimir_putin_o_kazakakh/4-1-0-20 (дата обращения: 14.04.2018).

${ }^{8}$ Опрос на Северном Кавказе 2017: коррупция и ухудшение экономического положения подрывают авторитет власти в регионе. URL: http:// caucasustimes.com/ru/opros-na-severnom-kavkaze2017-korrupcija-i-uhudshenie-jekonomicheskogopolozhenija-podryvaet-avtoritet-vlasti-v-regione/ (дата обращения: 14.04.2018).

9 Из бюджета Дагестана «испарились» 35 миллиардов рублей. URL: https://kavkaz.versia.ru/ iz-byudzheta-dagestana-isparilis-35-milliardov-rublej (дата обращения: 14.04.2018).

10 СКР объявил главу Пенсионного фонда Дагестана в международный розыск. URL: http:// www.rbc.ru/politics/28/07/2015/55b751309a 7947166734351f(дата обращения: 14.04.2018).

11 Опрос на Северном Кавказе 2017: коррупция и ухудшение экономического положения подрывают авторитет власти в регионе. URL: http:// caucasustimes.com/ru/opros-na-severnom-kavkaze2017-korrupcija-i-uhudshenie-jekonomicheskogopolozhenija-podryvaet-avtoritet-vlasti-v-regione/ (дата обращения: 14.04.2018).

12 Там же.

13 Там же.

\section{СПИСОК ЛИТЕРАТУРЫ}

1. Гуляихин, В. Н. Альтернативные модели правовой социализации человека: выбор аксиологических максим / В. Н. Гуляихин // Юридические исследования. - 2016. - № 1. - С. 65-84.

2. Гуляихин, В. Н. Архетипический базис правового воспитания личности / В. Н. Гуляихин, Е. В. Пантелеев // Философия права. -2017. - № 1. -С. 105-112.

3. Гуляихин, В. Н. Теория и практика правовой социализации в контексте актуальных политических ценностей / В. Н. Гуляихин, П. П. Фантров // Социум и власть. - 2016. - № 4. - С. 43-49. 
4. Зеленский, С. Н. Уголовно-процессуальные меры предупреждения нарушения принципа справедливости при обеспечении экологической безопасности / С. Н. Зеленский, Н. А. Соловьева // Правовая парадигма = Legal Concept. -2017 . - № 4. C. 149-156. - DOI: https://doi.org/10.15688/ lc.jvolsu.2017.4.21.

5. Фантров, П. П. Политический краудсорсинг в системе обеспечения национальной безопасности России / П. П. Фантров // Известия Саратовского университета. Серия: Социология, политология. 2017. - № 2. - С. 231-235.

6. Шинкарук, В. М. Проблемы законодательной регламентации признаков субъективной стороны хулиганства / В. М. Шинкарук // Вестник Волгоградского государственного университета. Серия 5, Юриспруденция. - 2016. - № 1. - С. 194-199.

\section{REFERENCES}

1. Gulyaikhin V.N. Alternativnye modeli pravovoy sotsializatsii cheloveka: vybor aksiologicheskikh maksim [Alternative Models of Legal Socialization of Human: the Choice of Axiological Maxims]. Yuridicheskie issledovaniya, 2016, no. 1, pp. 65-84.

2. Gulyaikhin V.N., Panteleev E.V.Arkhetipicheskiy bazis pravovogo vospitaniya lichnosti [Archetypical
Basis of Legal Education of a Person]. Filosofiya prava, 2017, no. 1, pp. 105-112.

3. Gulyaikhin V.N., Fantrov P.P. Teoriya i praktika pravovoy sotsializatsii $\mathrm{v}$ kontekste aktualnykh politicheskikh tsennostey [Theory and Practice of Legal Socialization in the Context of Current Political Values]. Sotsium i vlast, 2016, no. 4, pp. 43-49.

4. Zelenskiy S.N., Solovyeva N.A. Ugolovnoprotsessualnye mery preduprezhdeniya narusheniya printsipa spravedlivosti pri obespechenii ekologicheskoy bezopasnosti [Criminal Procedural Measures for Preventing Violation of the Equity Principle while Ensuring Ecological Security]. Pravovaya paradigma $=$ Legal Concept, 2017, no. 4, pp. 149-156.

5. Fantrov P.P. Politicheskiy kraudsorsing v sisteme obespecheniya natsionalnoy bezopasnosti Rossii [Political Crowdsourcing in the System of Ensuring National Security of Russia]. Izvestiya Saratovskogo universiteta. Seriya: Sotsiologiya, politologiya, 2017, no. 2, pp. 231-235.

6. Shinkaruk V.M. Problemy zakonodatelnoy reglamentatsii priznakov subyektivnoy storony khuliganstva [The Problems of Legislative Regulation of Signs of the Subjective Side of Hooliganism]. Vestnik Volgogradskogo gosudarstvennogo universiteta. Seriya 5, Yurisprudentsiya [Science Journal of Volgograd State University. Jurisprudence], 2016, no. 1, pp. 194-199.

\section{Information about the Authors}

Pavel P. Fantrov, Postgraduate Student, Teaching and Methodology Specialist, Department of Criminal Procedure and Criminalistics, Volgograd State University, Prosp. Universitetsky, 100, 400062 Volgograd, Russian Federation, pavelfantrov@volsu.ru.

Vladimir M. Shinkaruk, Candidate of Sciences (Jurisprudence), Associate Professor, Department of Criminal Procedure and Criminalistics, Volgograd State University, Prosp. Universitetsky, 100, 400062 Volgograd, Russian Federation, shinkaruk@volsu.ru, shinkarukvm@gmail.com.

\section{Информация об авторах}

Павел Петрович Фантров, аспирант, специалист по учебно-методической работе кафедры уголовного процесса и криминалистики, Волгоградский государственный университет, просп. Университетский, 100, 400062 г. Волгоград, Российская Федерация, pavelfantrov@volsu.ru.

Владимир Маркович Шинкарук, кандидат юридических наук, доцент кафедры уголовного процесса и криминалистики, Волгоградский государственный университет, просп. Университетский, 100, 400062 г. Волгоград, Российская Федерация, shinkaruk@volsu.ru, shinkarukvm@gmail.com. 